Research Article/Araştırma Makalesi

\title{
The Effects of Using Cabri and GeoGebra Software on the Geometric Shapes Reasoning Skills of Mathematics Prospective Teachers
}

\author{
Aziz ILHAN * 1 (D) Recep ASLANER 2 (D) \\ ${ }^{1}$ Munzur University, Faculty of Education, Tunceli, Turkey, tam.kare@gmail.com \\ 2 Inonu University, Faculty of Education, Malatya, Turkey, recep.aslaner@inonu.edu.tr \\ * Corresponding Author: tam.kare@gmail.com
}

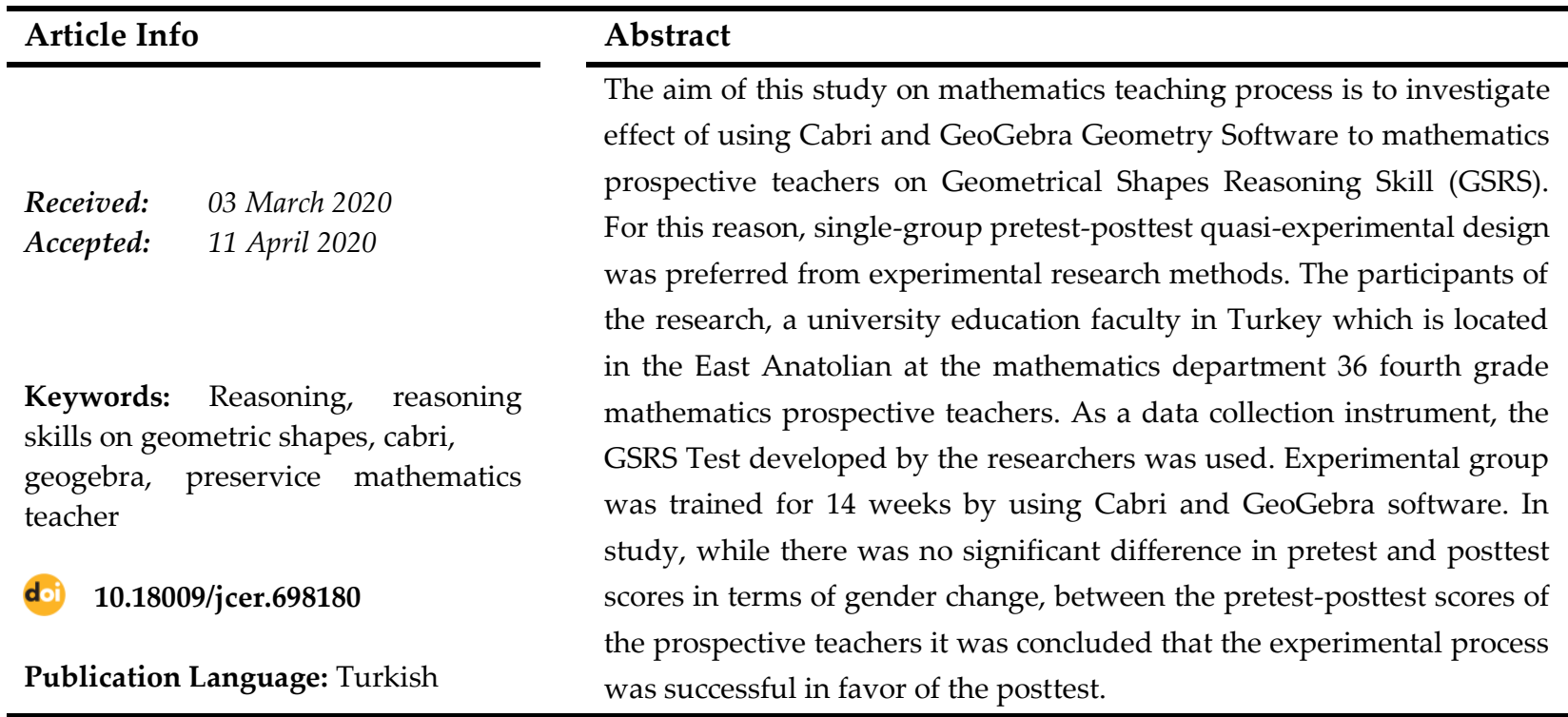

open access CrossMark (C)

To cite this article: İlhan, A. \& Aslaner, R. (2020). Cabri ve Geogebra yazılımları kullanımının, matematik öğretmen adaylarının geometrik şekiller üzerine akıl yürütme becerisine etkisi. Journal of Computer and Education Research, 8 (16), 386-403. DOI: 10.18009/jcer.698180

\section{Cabri ve GeoGebra Yazılımları Kullanımının, Matematik Öğretmen Adaylarının Geometrik Şekiller Üzerine Akıl Yürütme Becerisine Etkisi}

\begin{tabular}{|c|c|}
\hline Makale Bilgisi & $\ddot{\mathrm{Öz}}$ \\
\hline & $\mathrm{Bu}$ araştırmada amaç, matematik öğretim sürecinde Cabri ve GeoGebra \\
\hline 03 Mart 2020 & Yazılımları kullanımının matematik öğretmen adaylarının Geometrik \\
\hline 11 Nisan 2020 & $\begin{array}{l}\text { Şekiller Üzerine Akıl Yürütme Becerilerine (GŞAYB) etkisini } \\
\text { araştırmaktır. Bu sebeple araştırmada deneysel araştırma türlerinden } \\
\text { tek gruplu öntest-sontest yarı deneysel desen tercih edilmiştir. }\end{array}$ \\
\hline $\begin{array}{l}\text { Anahtar kelimeler: Akıl yürütme, } \\
\text { geometrik şekiller üzerine akıl } \\
\text { yürütme becerisi, cabri, geogebra, } \\
\text { matematik öğretmen adayları }\end{array}$ & $\begin{array}{l}\text { Çalışmanın katılımcılarını, Türkiye'nin Doğu Anadolu Bölgesindeki bir } \\
\text { üniversitede bulunan eğitim fakültesi matematik öğretmenliği } \\
\text { bölümünde öğrenim gören } 36 \text { dördüncü sınıf matematik öğretmen } \\
\text { adayı oluşturmaktadır. Çalışmada veri toplama aracı olarak } \\
\text { araştırmacılar tarafından geliştirilen GŞAYB Testi kullanılmıştır. Deney }\end{array}$ \\
\hline doi) $10.18009 /$ jcer.698180 & $\begin{array}{l}\text { grubuna } 14 \text { hafta boyunca Cabri ve GeoGebra yazılımları kullanılarak } \\
\text { eğitim yürütülmüşsür. Araştırmada cinsiyet değişkeni açısından öntest }\end{array}$ \\
\hline Yayım Dili: Türkçe & $\begin{array}{l}\text { ve sontest puanlarında anlamlı bir farklılık bulunmaz iken, öğretmen } \\
\text { adaylarının öntest-sontest GŞAYB puanları arasında sontest lehine } \\
\text { deneysel işlemin başarılı olduğu sonucuna ulaşılmıştır. }\end{array}$ \\
\hline
\end{tabular}




\title{
Summary
}

\section{The Effects of Using Cabri and GeoGebra Software on the Geometric Shapes Reasoning Skills of Mathematics Prospective Teachers}

\begin{abstract}
Introduction
Some of the appropriate information and communication technologies that can be used in mathematics education in order to provide the students with the aim of gaining the geometric thought and the aim of the education program are as follows in the Ministry of National Education (MoNE) mathematics curriculum: and their simulations, dynamic mathematics software (MoNE, 2013). In our country, mathematics education programs introduced by the MoNE emphasize the effective utilization of such software and propose that technology should be used as a main component instead of being an auxiliary tool in the teaching process. The concept of DGS, Geometer's Sketchpad, Cabri is used as the general name of software developed for geometry learning area. By entering the field of geometry teaching, (Güven \& Karatas, 2003). DGS has taken the geometry out of the paper-pencil process with a static or fixed structure and brought it to a dynamic state on the computer screen. Teachers can make their classes sensitized with better quality geometry problems. This situation improves students' ability to solve problems and their confidence towards them and their attitude towards mathematics positively affects them (Baki, 2001).
\end{abstract}

\section{Method}

The reasoning skills gained importance both in the national and international arena have been used in different genres in the literature and for the geometry field it has been expressed as GSRS. In addition, with the development of technology, dynamic software was found in teaching processes and used in educational processes including teaching programs. In this direction, the development of GSRS has been investigated by applying the DGS to the teacher candidates who will become teachers of mathematics in the future. The purpose of the research in this direction is to examine the effect of the use of DGS in the mathematics teaching process on the effects of mathematics teacher candidates on GSRS. For this reason, single-group pretest-posttest quasi-experimental design was preferred from experimental 
research methods. The participants of the research, a university education faculty in Turkey are which is located in the East Anatolian 2016-2017 academic year in the fall semester studying at the mathematics department 36 fourth grade prospective math teacher. As a data collection instrument, the GSRS Test developed by the researchers was used. SPSS 23.0 program was used for analysis of the data. Experimental group was trained for 14 weeks by using Cabri II Plus and GeoGebra software. At the beginning and end of the training period, the GSRS Test was applied as a pretest-posttest.

\section{Results}

As a result, it is possible to say that DGS are important in increasing the GSRS levels of mathematics teacher candidates. In order to investigate the development of GSRS on different sample groups by using researchers' to DGS who want to work with GSRS in the future and to investigate GSRS using control group experimental design and to improve the GSRS of mathematics teachers, training is recommended.

\section{Discussion and Conclusion}

In the study, descriptive statistics related to the general meaning and gender variable of the data obtained from the GSRS Test were examined in order to reasoning skills of the mathematics teacher candidates. When these statistics were examined, it was seen that the posttest average scores of the reasoning skills of the sample were almost doubled according to the pretest scores. When the research data are analyzed according to the gender variable, it is seen that the posttest average scores of both female and male mathematics teacher candidates are almost doubled according to the pretest scores of GSRS Test. For this reason, prospective mathematics teachers have learned not only procedural skills but also conceptual knowledge at the same time in the teaching process. Akkus-Cikla and Duatepe (2002) stated that mathematics teacher candidates have operational knowledge after reasoning, but they do not have conceptual knowledge at all. They also stated that the learning process is effective when conceptual information is obtained. In this study, it is possible to say that the reasoning skills of prospective mathematics teacher increase on the conceptual (geometric shapes) as a result of the execution of the learning process by using DGS. After examining the descriptive statistics in the study, it was determined that the pretest and posttest scores of the prospective mathematics teachers differed significantly with respect to the gender variable and it was determined that the scores of the male and 
female prospective mathematics teachers did not show any significant difference according to both pretest and posttest scores. As a result of this finding in the study, it is possible to say that the mathematics teacher candidates have similar reasoning skills before the teaching process and that they have developed reasoning skills in a similar way due to the completion of the teaching period with the use of DGS. Buyukozturk, Cakmak, Akgun, Karadeniz and Demirel (2016) stated that the individuals who are taken into the research sample should have similar characteristics before and after the experimental period. This finding is similar to the result of the research. In the study, it was investigated by $\mathrm{t}$-test in dependent groups that the reasoning skills of female, male and all mathematics teacher candidates showed a meaningful difference according to the pretest and posttest scores. According to the test results, there was a significant difference between posttest and pretest scores of female, male and all mathematics teacher candidates respectively. When we look at the average, it is seen that this difference is favored to posttest for all three sample groups. The reason for this can be seen as the fact that the teaching period has been enriched by the DGS practices and the interest or positive attitude towards the course has increased. Aktumen and Kacar (2003) obtained the results that computer-assisted geometry teaching positively affects the achievements and attitudes of mathematics teachers in their studies. Bedir (2005) also stated that his study of computer-assisted instruction has increased the success of his students. These results are similar to those obtained in the study. 


\section{Giriş}

Bilgisayar destekli eğitimin geometri öğretiminde kullanılmasıyla, öğrenenlerin geometrik bir şeklin parçaları arasında bulunan ilişkileri görmeleri sağlanmış, sınıfların sanal laboratuvar ortamlarına dönüştürülebileceği vurgulanmıştır (Güven, 2002). Bu tür bir eğitimin en önemli aracı, dinamik geometri yazılımları genel ismiyle bilinen, öğrenenlerin bilgisayarda geometrik şekilleri doğrudan ve dinamik biçimde hareket ettirebileceği şekilde tasarlanmış yazılımlardır (Gomes \& Vergnaud, 2004). Dinamik yazılımlarının kendisine özgü olan özellikleri bireylere geometriyi dinamik bir şekilde inceleme fırsatı vermektedir. $\mathrm{Bu}$ yazılımlardan Cabri ve GeoGebra programları sayesinde öğrenenler, kendileri için karmaşık gelen olguları bilgisayar ortamında görselleştirerek akıllarında bulunan düşünceleri ekranda temsil edip somutlaştırabilirler (Gomes \& Vergnaud, 2004). Ayrıca girdilere karşılık bilgisayar ekranındaki çıktıları gözleyerek tahminde bulunabilme ve bu tahminlerini test edebilme olanağına sahip olabilirler (Baki, 2001). Yine Cabri programı sayesinde, öğrenciler farklı türde şekiller oluşturabilir. Bilgisayarların üretmiş olduğu şekillere anlam vermek onların o kavram ile ilgili bilişsel görüntülerini veya şemalarını zenginleştirir (Tall, Blockland, \& Kok, 1990).

Öğretim programında hedeflenen kazanımların öğrenciye kazandırılması ve geometrik düşüncenin geliştirilmesi amacıyla matematik eğitiminde kullanılabilen uygun bilgi ve iletişim teknolojilerinin bir kısmı 2013 Milli Eğitim Bakanlığı (MEB) matematik öğretim programında şöyle ifade edilmiştir: dinamik geometri yazılımları, grafik çizim yazılımları, bilgisayarlardaki cebir sistemleri, dinamik istatistik yazılımları ve simülasyonları, elektronik tablo çizimi yazılımları, dinamik matematik yazılımları (MEB, 2013). Ülkemizde MEB tarafından uygulamaya konulan matematik öğretim programları bu tür yazılımlardan etkin bir şekilde yararlanılmasını vurgulamakta, teknolojinin öğretim sürecinde yardımcı bir araç olmak yerine, ana bir bileşen olarak uygulamalarda bulunmasını önermektedir. Dinamik geometri yazılımı kavramı, Geometer's Sketchpad, Cabri Geometry gibi geometri öğrenme alanı için geliştirilmiş yazılımların genel adı olarak kullanılmaktadır. Dinamik yazılımlar geometri öğretimi alanına girerek, geometriyi sabit bir yapıya sahip kâğıt-kalem süreçlerinden çıkarıp bilgisayar ekranında dinamik bir duruma getirerek, öğrencilerin varsayımlarda bulunmalarına, teoremler ve arasındaki ilişkileri keşfetmelerine ve denemelerine imkân oluşturmuştur (Güven \& Karataş, 2003). Dinamik geometri yazılımları kullanılarak öğretmenler sınıflarını daha kaliteli geometri problemleriyle duyarlı 
hale getirebilir. Bu durum öğrenenlerin problemleri çözebilme becerilerini geliştirdiği kadar kendilerine olan güvenlerini ve matematiğe karşı geliştirmiş oldukları tutumlarını olumlu yönde etkilemektedir (Baki, 2001).

Dinamik geometri yazılımları, öğretim sürecinde bulunan soyut olan kavramları görsel hale getirme, eksiksiz çizimler yapabilme ve örnekleri istenen durumlarıyla arttırabilme gibi özellikleri sayesinde geometri öğrenme alanı konularının öğretimi sürecinde kullanılır (Altun, 2009, ss.298-308). Bu, dinamik geometri yazılımlarının öğretim sürecinde kullanımı sayesinde bireylerin düşünme becerileri gelişim göstermektedir. Düşünme becerileri yaratıcı düşünme, problem çözme, karar verebilme, değerlendirme yapabilme ve akıl yürütmeye ilişkin öğretim süreçlerine yer veren destekleyici elemanların öğretim sürecinde kullanılmasıyla öğretilir. Dinamik geometri yazılımları sayesinde birey düşünme becerilerini geliştirir, kanıtlara dayalı ifade ettiği düşünceler için belirli nedenler sunar ve ikilemleri çözebilmek amacıyla bilimsel akıl yürütme gibi gerçekçi yollar kullanır (Köseoğlu, Tümay, \& Budak, 2008). Düşünme türlerinin öğrenme-öğretme ortamlarında uygulanması; kişisel yeteneklere dayanan akademik başarıya katkı sağlar, kişilerin öğrenme biçimlerini tanımalarına yardımcı olur (Çubukçu, 2004). National Research Council [NRC] (1996), matematik eğitiminde amacın, kişinin bilimsel düşünce becerilerini geliştirmeye dönük olduğunu belirtmektedir. NRC (1996)'ye göre bir eğitim ortamı, kişiye matematiğin veya bilim ve teknolojinin bütün içeriğini aktarmaya dönük olmaktan ziyade, akıl yürütme becerilerini kazandırmaya yönelik olmalıdır.

Öğreten merkezli teorik bilgiyi öğretmeye yönelik öğretim süreçlerinin, bilimsel akıl yürütme becerilerini geliştirmeye ciddi anlamda bir desteğinin olmadı̆̆ını; bilimsel bilgiyi kazandırmaya dönük öğretim süreçlerinin ise akıl yürütmeler üzerinde pozitif etkisinin olduğunu ifade etmek mümkündür (Lawson, 2005). Akıl yürütme; tüm etmenleri göz önünde bulundurarak ve düşünerek bir sonuca varma sürecidir. Akıl yürütebilen bir birey; konu hakkında yeteri kadar bilgiye sahiptir, yeni karşılaştığı durumu bütün boyutlarıyla araştırır, keşifler yapar, mantıklı varsayımlarda ve tahminlerde bulunur, düşündüklerini faaliyete geçirir, birtakım sonuçlara ulaşır, ulaştığı sonuçları açıklayabilir veya savunabilir (Umay, Duatepe-Akkuş, \& Çıkla, 2005). Oaksford (2005) insanların akıl yürütme süreçlerine oldukça bağımlı olduklarını ve bu nedenle bu süreci fark etmeme eğiliminde olduklarını belirtmiştir. Bununla beraber, insanların yaptıkları çoğu hareketin akıl yürütme süreçlerine bağlı olduğunu öne sürmüştür. Bu kavram sadece bu alanlarla değil bu alanların kapsadığ 
konularla da yakından ilişkilidir. Bu sebeple akıl yürütme terimi, sayısız konu ve içeriğini kapsayan geniş bir düşünme durumunu tarif etmek için kullanılmaktadır ve karmaşık bilişsel süreçlerden biridir. Aynı zamanda bilinçli bir bilişsel aktivitedir, hedefe yöneliktir ve bir dizi işlem veya basamak gerektirir (Amsterlaw, 2004). Akıl yürütme kavramının kullanılmasıyla beraber karışık öğretim süreçlerini daha doğal bir öğretim ortamına dönüştüren dinamik geometri yazılımları ve bilgisayarlarda bulunan cebir sistemleri gün geçtikçe artan bir şekilde öğretim sürecinde kullanılmaktadır. Bu tür yazılımlar sayesinde öğrenenler akıl yürütme becerisi kazanabilmekte, matematiksel ilişkileri keşfedebilmekte, birbirleriyle ilişkilendirebilmekte ve doğru genellemelere ulaşabilmede bu yazılımları etkili bir şekilde kullanabilmektedir (Güven, 2002). Bilgisayar destekli öğretim sürecinden yararlanabilmek, bu amaca hizmet edebilecek etkili ve dinamik eğitim yazılımlarının geliştirilmesiyle yakın ilişki içerisindedir (Baki, 2001). Bundan ötürü bilgisayar destekli matematik eğitimi için son zamanlarda dinamik yazılımları geliştirme çabalarının hızlandığı ifade edilmektedir (Topuz \& Birgin, 2014). Dinamik geometri yazılımlarının geliştirilmesi ve akıl yürütme kavramının öğretim ortamlarında yer bulmasılla beraber bu iki kavram arasındaki ilişkiyi destekleyen ve inceleyen çalışmalara alan yazında yer verilmeye başlanmıştır. Southampton ve Hampshire'da bir grup matematikçi ve destekleyici eğitimci, ortaokulda geometrik akıl yürütmenin geliştirilmesi ve odaklanılması gerektiğini belirten bir rapor yazmışlardır. Raporda geometrik akıl yürütme kavramının iki ve üç boyutlu cisimlerin özelliklerini, durumlarını, yönlerini ve dönüşümlerini içerdiği belirtilmiştir (Brown, Jones, \& Taylor, 2003). Royal Society ve Joint Mathematical Council (2001) yazmış olduğu raporda 1119 yaş aralığındaki öğrencilerin geometri öğrenme süreçlerinde kullanılan yazılımların ve geometrik akıl yürütme kavramının önemli olduğunu dile getirmiştir.

Geometrik düşünce süreçleri incelendiğinde tüm basamakların öğretim sürecine dâhil edilmesi ve uygulanması için dinamik geometri yazılımları ve öğretim sürecinde kullanılan materyaller ön plana çıkmaktadır. Öğreticilerin öğretim materyallerini uygun olan yöntemler veya tekniklerle yerinde ve doğru bir şekilde kullanmaları, öğrenene iletmek istediği mesajı görsel bir şekilde düzenleyebilmesi, basit şekilde şemalar ve çizimler yapabilmesi bilişsel becerilerinden üst düzeyde etkilenebilmektedir (Alpan, 2008). Buna karşın Aydın, Laçin ve Keskin (2018) öğretmenlerin ders ortamlarında matematiksel yazılımları yeteri kadar kullanmadığını ifade etmişlerdir. Alan yazın taraması yapıldığında akıl yürütme, geometrik akıl yürütme, iki ve üç boyutlu geometrik şekiller üzerine akıl 
yürütme gibi akıl yürütme türleri ve dinamik geometri yazılımlarının kullanımı üzerine yurt dışında çeşitli çalışmalar yapıldığı görülmektedir (Amsterlaw, 2004; Lawson, 2005; Oaksford, 2005). Ancak yurt içinde akıl yürütme türleri ile ilgili daha az çalışma örneğine rastlanmakta, bu çalışmalarda ise genellikle örneklemin akıl yürütme becerilerinin orta veya düşük seviyede olduğu görülmektedir (Çubukçu, 2004). Ayrıca bu dinamik geometri yazılımlarının kullanıldığı çalışmalarda genellikle akıl yürütme veya bilişsel süreçler yerine başarı, uygulanabilirlik, pedagojik yaklaşımlar veya öğrenci görüşleri incelenmiştir (Akar \& Hacısalihoğlu-Karadeniz 2014; Çiftçi \& Tatar, 2014; İbili, 2019; Topuz \& Birgin, 2020). Dolayısıyla alternatif bir öğrenme yöntemi olan bilgisayar destekli öğretim yöntemi ile dinamik yazılımların kullanımı akıl yürütme becerisinin arttırılması için bir öngörü olarak düşünülmüştür. $\mathrm{Bu}$ nedenlerle matematik öğretmen adaylarının GŞAYB düzeylerinin dinamik geometri yazılımlarının kullanıldığı öğretim ortamlarıyla ilişkilendirilerek ölçülmemesi bir eksiklik olarak görülmüştür. Teknolojinin hızlı bir şekilde gelişmekte olduğu, bilgisayarların ve dinamik yazılımların öğretim süreçlerine entegre edildiği, akıl yürütme becerilerinin öğretim programlarında (MEB, 2018) kazandırılması gereken temel beceriler arasında yer aldığı günümüzde araştırmanın alan yazına önemli derecede katkı sağlayacağı düşünülmektedir.

\section{Araştırmanın Amacı ve Alt Amaçlar}

$\mathrm{Bu}$ araştırmada amaç, matematik öğretiminde Cabri ve GeoGebra kullanımının matematik öğretmen adaylarının GŞAYB’lerine etkisini araştırmaktır. Bu genel amaç doğrultusunda aşağıda verilen alt amaçlar belirlenmiştir. Matematik öğretmen adaylarına yönelik Cabri ve GeoGebra kullanılan öğretim sürecine ilişkin;

1. Uygulama öncesi ve sonrası matematik öğretmen adaylarının GŞAYB düzeyleri nasıldır?

2. Uygulama öncesi ve sonrası cinsiyet değişkenine göre matematik öğretmen adaylarının GŞAYB düzeyleri nasıldır?

3. Matematik öğretmen adaylarının öntest GŞAYB puanları cinsiyet değişkeni açısından anlamlı farklılık göstermekte midir?

4. Matematik öğretmen adaylarının sontest GŞAYB puanları cinsiyet değişkeni açısından anlamlı farklılık göstermekte midir?

5. Matematik öğretmen adaylarının öntest-sontest GŞAYB puanları anlamlı farklılık göstermekte midir? 


\section{Yöntem}

\section{Araştırmanın Deseni}

$\mathrm{Bu}$ araştırmanın amacı matematik öğretiminde Cabri ve GeoGebra kullanımının matematik öğretmen adaylarının GŞAYB’lerine etkisini araştırmaktır. Bu sebeple çalışmada tek gruplu öntest-sontest yarı deneysel desen tercih edilmiştir. Bu desene göre 14 haftalık bir öğretim süreci yürütülmüş, bu sürecin öncesinde ve sonrasında GŞAYB Testi öntest ve sontest olarak deney grubuna uygulanmıştır. Tek grup öntest-sontest modelinde, seçilen katılımcı gruba deney süreci uygulanır. Hem deney öncesinde hem de deney sonrasında ölçümler yapılır. Modelin simgesel ifadesi şu şekildedir:

G1: Q1.1--------- X ---------- $Q_{1.2 `}$ dir.

[G1: Araştırma katılımcıları, Q1.1: Birinci ölçüm (öntest), X: Eğitim-öğretim faaliyetleri (Cabri ve GeoGebra Uygulamaları), O1.2: ikinci ölçüm (sontest)]

Modelde $\mathrm{Q}_{1.2}>\mathrm{Q}_{1.1}$ olması durumunda bunun $\mathrm{X}$ uygulamasından (Cabri ve GeoGebra Uygulamalarından) kaynaklandığı kabul edilmektedir ve bu doğrultuda değerlendirme yapılmaktadır (Karasar, 1991). Araştırmada bu desenin seçilmesinin nedeni ilgili üniversitenin matematik öğretmenliği bölümü dördüncü sınıf öğretim programında bulunan ve seçmeli geometri öğretimi dersini seçen öğretmen adayı sayısının yetersiz olması (Programda ilgili dönemde kayıtlı 60 öğretmen adayı bulunmaktadır. Açılan iki adet seçmeli ders mevcuttur. Diğer seçmeli ders matematik eğitimi alanındadır fakat geometri öğrenme alanıyla ilişkili değildir. Dolayısıyla öğrencilerin yarıya yakını yani 36 matematik öğretmen adayı bu dersi seçmiştir) ve bu dersin benzeri bir dersin açılamamasıdır. Dolayısıyla, araştırma sadece deney grubu uygulamalarıyla yürütülmüş, kontrol grubuna yer verilememiştir.

\section{Evren-Örneklem}

Araştırmanın katılımcılarını, Türkiye'nin Doğu Anadolu bölgesinde bir üniversitede bulunan eğitim fakültesinde 2016-2017 güz döneminde ilköğretim matematik öğretmenliği programında öğrenim görmekte olan ve seçmeli geometri öğretimi dersini alan 36 (24 kadın, 12 erkek) 4. sınıf matematik öğretmen adayı oluşturmaktadır. Araştırmada örnekleme yöntemi olarak uygun örnekleme yöntemi tercih edilmiştir. Bu örnekleme yönteminin seçilmesinin sebebi ilgili grubun çalışma amacına uygun olan seçmeli dersi gönüllü bir şekilde seçmiş olması ve geometri öğretimi dersinin öğrenme çıktılarının GŞAYB ile ilişkili 
olmasıdır. Ayrıca araştırmacılardan birinin ilgili üniversitede çalışıyor olması zaman ve işgücü kolaylığı sağlamıştır. Uygun örnekleme yöntemi; zaman, para ve işgücü açısından var olan sınırlılıklar nedeniyle örneklemin kolay ulaşılabilir ve uygulama yapılabilir birimlerden seçilmesidir (Büyüköztürk, Çakmak, Akgün, Karadeniz, \& Demirel, 2016).

\section{Veri Toplama Araçları}

Araştırmacılar tarafından geliştirilmiş GŞAYB testi çoktan seçmeli olup toplam 20 maddeden oluşmaktadır. Testte bulunan maddeler Türkiye'de bulunan lisans düzeyinde yürütülen geometri öğretimi derslerinin öğrenme çıtıları ve uluslararası alan yazında bulunan GŞAYB'e ilişkin çalışmalar dikkate alınarak oluşturulmuştur. Testin geçerlilik ve güvenirlik çalışmaları bu araştırma öncesinde 266 kişilik araştırma örnekleminden farklı bir katılımcı grubu ile yürütülmüştür. Bu doğrultuda testin KR-20 güvenirlik değeri 0.745 olarak hesaplanmıştır.

Ayrıca bu çalışmada GSAYB'un güvenirlik değeri 0,722 çıkmıştır. Bu değerler 0.70'den büyük olduğundan testin güvenilir olduğunu söyleyebilmek için yeterlidir (Büyüköztürk, Çakmak, Akgün, Karadeniz \& Demirel, 2016). Araştırmada GŞAYB testi maddeleri doğru cevaplar için 1 yanlış cevaplar için 0 olacak şekilde puanlandırılmıştır. Bu nedenle GŞAYB Testinden alınabilecek en düşük puan 0 en yüksek puan ise 20' dir.

\section{Veri Toplama Süreci}

Çalışmada deney grubuna uygulama sürecinin ilk haftasında deney süreci hakkında bilgi verilmiştir. Daha sonra ön test olarak GŞAYB Testi uygulanmıştır. İkinci haftadan itibaren sırasıyla birer etkinlik yapılmıştır. Bu etkinlikler tasarlanırken alan yazın taranmış, dersin kazanımları göz önünde bulundurulmuş, GŞAYB testinin maddeleri değerlendirilmiş ve uzman görüşüne başvurulmuştur. Etkinlik uygulamaları yapılırken ilk dört hafta gösterip yaptırma tekniği tercih edilmiş, takip eden haftalarda buluş yoluyla öğretim süreci yürütülmüştür. Öğretmen adaylarına takıldıkları noktalarda küçük ipuçları verilerek etkinlik dosyalarını oluşturmaları istenmiştir. Öğretmen adayları her hafta oluşturdukları etkinlik dosyalarını araştırmacının mail adresine yollamış, araştırmacılar etkinlikleri kontrol ederek dönüt vermiştir. Etkinlik sürecinin on dördüncü haftasında genel bir tekrar yapılmış ve öğretmen adaylarına GŞAYB Testi son test olarak tekrar uygulanmıştır. Haftalara göre yürütülen etkinlik süreci ekte verilmiştir. 


\section{Verilerin Analizi}

Çalışmada varyansların homojen dağılıp dağılmadığını belirlemek amacıyla öncelikle Levene testi yapılmıştır. Levene testi sonucu GSAYB testi $(Z=0,392, p=0,163)$ uygulamaları için p>0,05 olduğundan varyansların homojen dağıldığı tespit edilmiştir (Büyüköztürk, 2016). Varyansların homojenliğinin incelenmesi sonrasında çarpıklık ve basıklık değerleri analiz edilmiş bu değerlerin -2 ile +2 arasında olduğu, z-çarpıklık ve z-basıklık değerlerinin ise -1.96 ile +1.96 aralığında bulunduğu belirlenmiştir. Bununla birlikte mod, medyan ve aritmetik ortalamanın da birbirine yakın olduğu görülmüştür (Büyüköztürk, 2016, ss. 40-68). Ayrıca verilerin normal dağılıp dağılmadığını belirlemek amacıyla Shapiro-Wilk testi yapılmıştır. Bu teste ilişkin bulgular Tablo 1 de verilmiştir.

Tablo 1. GŞAYB testi Shapiro-Wilk testi sonuçları

\begin{tabular}{lcccc}
\hline & Grup & İstatistik & Sd & $p$ \\
\hline \multirow{2}{*}{ GŞAYB testi } & Bayan & 0,970 & 23 & 0,200 \\
& Erkek & 0,960 & 11 & 0,330 \\
\hline
\end{tabular}

Büyüköztürk (2016, s. 42) grup büyüklügünün 50 den küçük olması durumunda Shapiro-Wilks testinin, puanların normalliğe uygunluğunu incelemede kullanılacağını ifade etmiştir. Bu sebeple Shapiro-Wilk testi tercih edilmiştir. Bu testin sonucunda GSAYB testi uygulamalarının her bir veri seti için $(p>0,05)$ olduğu ve normal dağılım gösterdiği belirlenmiştir. Veriler normal dağılım gösterdiği için, ikili gruplarda varyansların eşit olduğu gruplar için (Equalvariances essumed) t-testi kullanılmasına karar verilmiştir (Büyüköztürk, 2016). Böylece çalışmada öncelikle öğretmen adaylarının öntest-sontest puanlarına ilişkin genel anlamda ve cinsiyet değişkenine göre betimsel istatistikler araştırılmıştır. Daha sonra, cinsiyet değişkeni açısından öntest ve sontest puanlarının anlamlı bir farklılık gösterip göstermediğini tespit etmek amacıyla bağımsız örneklem t-testi, Cabri ve GeoGebra kullanılan öğretim sürecinin yürütülmesi neticesinde cinsiyet değişkenine göre ve genel anlamda GŞAYB puanlarının anlamlı farklılık gösterip göstermediğini belirlemek amacıyla bağımlı gruplarda t-testi sonuçları araştırılmıştır.

\section{Bulgular}

Çalışmanın bu bölümünde matematik öğretmen adaylarının Cabri ve GeoGebra kullanılarak yürütülen öğretim sürecine ilişkin öntest-sontest puanlarına ait bulgular genel 
anlamda ve cinsiyet değişkenine göre verilmiştir. Matematik öğretmen adaylarının, GŞAYB Testinden elde edilen ortalama, standart sapma ve yüzde değerleri Tablo 2' de verilmiştir.

Tablo 2. Öntest-sontest puanlarına ilişkin betimleyici istatistikler

\begin{tabular}{ccccccc}
\hline & $\mathrm{N}$ & Min. & Maks. & $\overline{\mathrm{X}}$ & $\%$ & $\mathrm{Ss}$ \\
\hline Öntest & 36 & 2.000 & 11.000 & 5.889 & 29.445 & 2.754 \\
\hline Sontest & 36 & 7.000 & 16.000 & 11.778 & 58.890 & 2.439 \\
\hline
\end{tabular}

Tablo 2 incelendiğinde öğretmen adaylarının öntest ortalamalarının $\bar{X}=5.889$, standart sapmalarının Ss=2.754 olduğu görülmektedir. Bu veriye göre matematik öğretmen adaylarının öntest GŞAYB düzeylerinin (\%29.445) düşük olduğunu söylemek mümkündür. Ayrıca öğretmen adaylarının sontest ortalamaları $\bar{X}=11.778$, standart sapmaları Ss=2.439 olarak hesaplanmıştır. Yani öğretmen adaylarının deneysel süreç sonunda GŞAYB düzeylerinin \%59.890’a yükseldiği görülmektedir. Öğretmen adaylarının GŞAYB Testinden elde edilen genel puanlarının betimleyici istatistikleri incelendikten sonra cinsiyet değişkenine ilişkin betimleyici istatistikler araştırılmış, elde edilen bulgular Tablo 3'te verilmiştir.

Tablo 3. Öntest-sontest puanlarına ilişkin cinsiyet değişkenine bağlı betimleyici istatistikler

\begin{tabular}{cccccccc}
\hline & Cinsiyet & $\mathrm{N}$ & Min. & Maks. & $\overline{\mathrm{X}}$ & $\%$ & \multicolumn{2}{c}{ Ss } \\
\hline \multirow{2}{*}{ Ön test } & Bayan & 24 & 2.000 & 11.000 & 5.458 & 27.290 & 2.553 \\
\cline { 2 - 8 } & Erkek & 12 & 2.000 & 11.000 & 6.750 & 33.750 & 3.048 \\
\hline \multirow{2}{*}{ Son test } & Bayan & 24 & 7.000 & 15.000 & 11.667 & 58.335 & 2.334 \\
\cline { 2 - 8 } & Erkek & 12 & 8.000 & 16.000 & 12.000 & 60.000 & 2.730 \\
\hline
\end{tabular}

Tablo 3 incelendiğinde bayan öğretmen adaylarının öntest ortalamalarının $\bar{X}=5.458$, standart sapmalarının Ss=2.553 olduğu, erkek öğretmen adaylarının öntest ortalamalarının $\bar{X}=6.750$, standart sapmalarının $\mathrm{Ss}=3.048$ olduğu görülmektedir. Yani öntest verilerine göre erkeklerin bayanlara göre GŞAYB düzeyleri daha yüksek çıkmıştır. Ayrıca bayan öğretmen adaylarının sontest ortalamalarının $\overline{\mathrm{X}}=11.667$, standart sapmalarının Ss=2.334 olduğu, erkeklerin sontest ortalamalarının $\bar{X}=12.000$, standart sapmalarının Ss=2.730 olduğu tespit edilmiştir. Sontest verilerine göre de erkeklerin GŞAYB düzeyleri bayanlara göre daha yüksek çıkmıştır. Öğretmen adaylarının GŞAYB Testinden elde edilen cinsiyet değişkenine ilişkin puanlarının betimleyici istatistikleri analiz edildikten sonra öntest-sontest puanlarının 
cinsiyet değişkenine göre bağımsız örneklem t-testi sonuçları araştırılmıştır. Elde edilen bulgular Tablo $4^{\prime}$ te verilmiştir.

Tablo 4. Öntest-sontest puanlarının cinsiyet değişkenine ilişkin bağımsız örneklem t-testi sonuçları

\begin{tabular}{|c|c|c|c|c|c|c|c|}
\hline & Cinsiyet & $\mathrm{N}$ & $\overline{\mathrm{X}}$ & Ss & Sd. & $t$ & $\mathrm{p}$ \\
\hline \multirow{2}{*}{ Ön test } & Bayan & 24 & 5.458 & 2.553 & \multirow{2}{*}{35} & \multirow{2}{*}{-1.263} & \multirow{2}{*}{0.222} \\
\hline & Erkek & 12 & 6.750 & 3.048 & & & \\
\hline \multirow{2}{*}{ Son test } & Bayan & 24 & 11.667 & 2.334 & \multirow{2}{*}{35} & \multirow{2}{*}{-0.362} & \multirow{2}{*}{0.721} \\
\hline & Erkek & 12 & 12.000 & 2.730 & & & \\
\hline
\end{tabular}

Tablo 4 incelendiğinde matematik öğretmen adaylarının hem öntest puanlarının $(t(35)=-1.263: p>0.05)$ hem de sontest puanlarının cinsiyet değişkenine göre anlamlı bir farklılık göstermediği $(\mathrm{t}(35)=-0.362: \quad \mathrm{p}>0.05)$ tespit edilmiştir. Matematik öğretmen adaylarının öntest ve sontest puanlarının cinsiyet değişkenine göre bağımsız örneklem t-testi sonuçları incelendikten sonra cinsiyet değişkenine göre öntest-sontest bağımlı örneklem ttesti sonuçları incelenmiş, elde edilen bulgular Tablo 5'te verilmiştir.

Tablo 5. Cinsiyet değişkenine ilişkin puanlarının bağımlı örneklem t-testi sonuçları

\begin{tabular}{|c|c|c|c|c|c|c|c|}
\hline & & $\mathrm{N}$ & $\overline{\mathrm{X}}$ & Ss. & Sd. & $\mathrm{t}$ & $\mathrm{p}$ \\
\hline \multirow{2}{*}{ Bayan } & Ön test & 24 & 5.458 & 2.553 & \multirow{2}{*}{23} & \multirow{2}{*}{10.472} & \multirow{2}{*}{0.000} \\
\hline & Son test & 24 & 11.667 & 2.334 & & & \\
\hline \multirow[b]{2}{*}{ Erkek } & Ön test & 12 & 6.750 & 3.048 & \multirow[b]{2}{*}{11} & \multirow[b]{2}{*}{7.669} & \multirow[b]{2}{*}{0.000} \\
\hline & Son test & 12 & 12.000 & 2.730 & & & \\
\hline
\end{tabular}

Tablo 5 verileri incelendiğinde hem bayan öğretmen adaylarının öntest-sontest puanları arasında $(t(23)=10.472: p=0.000<0.05)$ hem de erkek öğretmen adaylarının öntest-sontest puanları arasında anlamlı farklılık $(\mathrm{t}(11)=7.669: \mathrm{p}=0.000<0.05)$ olduğu tespit edilmiştir. Bayan öğretmen adaylarının öntest ve sontest puan ortalamalarına bakıldığında $\left(\overline{\mathrm{X}}_{\text {sontest }}=11.667\right.$; $\left.\bar{X}_{\text {öntest }}=5.458\right)$ bu farklılığın son testin lehine olduğu sonucuna varılmıştır. Yine erkek öğretmen adaylarının öntest ve sontest puan ortalamalarına bakıldığında $\left(\bar{X}_{\text {sontest }}=11.667\right.$; $\left.\bar{X}_{\text {öntest }}=5.458\right)$ bu farklılığın son testin lehine olduğu görülmektedir. Araştırmada öğretmen adaylarının GŞAYB Testi öntest-sontest sonuçlarının anlamlı bir farklılık oluşturup oluşturmadığı bağımlı örneklem t-testi ile araştırılmış, elde edilen bulgular Tablo 6'da verilmiştir.

Tablo 6. Öntest ve sontest bağımlı örnekleme ait t-testi sonuçları

\begin{tabular}{lcccccc}
\hline Uygulama & $\mathrm{N}$ & $\overline{\mathrm{X}}$ & Ss. & Sd. & $\mathrm{t}$ & $\mathrm{p}$ \\
\hline Ön test & 36 & 5.889 & 2.754 & \multirow{2}{*}{35} & \multirow{2}{*}{10.254} & \multirow{2}{*}{0.000} \\
\hline Son test & 36 & 11.778 & 2.439 & & & \\
\hline
\end{tabular}


Tablo 6 incelendiğinde tüm öğretmen adaylarının öntest-sontest puanları arasında anlamlı bir farklılığın oluştuğu $(t(35)=-10.254: p<0.05)$ görülmektedir. Öğretmen adaylarının öntest ve sontest puan ortalamalarına bakıldı ğında $\left(\bar{X}_{\text {sontest }}=11.778 ; \bar{X}_{\text {öntest }}=5.889\right)$ bu farklılığın son testin lehine olduğu sonucuna ulaşılmıştır.

\section{Tartışma, Sonuç ve Öneriler}

2005'te yapılan MEB matematik program değişikliğiyle akıl yürütme becerisi öğrencilere kazandırılması gereken temel beceriler arasına alınarak ön plana çıkmıştır. MEB yapmış olduğu çalışmalarla öğretim süreçlerinde kullanılan ders kitapları ve çalışma kitaplarına akıl yürütme ile ilgili etkinlikler eklemiş, öğretim ortamındaki akıl yürütme etkinliklerinin önemine değinmiştir (MEB, 2005-2013-2018). Ayrıca NRC, 1996 yılı itibariyle matematik eğitiminde akıl yürütme becerilerini kazandırmaya yönelik amaçlar bulunması gerektiğini ifade etmiştir. Hem ulusal hem de uluslararası alanda önem kazanan akıl yürütme becerisi alan yazında farklı türlerde kullanılmış, geometri alanı için de GŞAYB olarak ifade edilmiştir. Ayrıca teknolojinin gelişimiyle beraber dinamik yazılımlar öğretim süreçlerinde yer almış ve öğretim programlarına da dâhil edilmiştir. Bu doğrultuda çalışmada öğretmen adaylarına Cabri ve GeoGebra uygulamaları yapılarak GŞAYB düzeylerindeki gelişimleri araştırılmıştır.

Araştırmada öncelikle matematik öğretmen adaylarının akıl yürütme becerilerini incelemek amaciyla GŞAYB Testinden elde edilen verilerin genel anlamda ve cinsiyet değişkenine ilişkin betimleyici istatistikleri incelenmiştir. $\mathrm{Bu}$ istatistikler incelendiğinde örneklemin bütününe ilişkin akıl yürütme becerisine ait sontest ortalama puanlarının öntest puanlarına göre neredeyse iki katına çıtı̆̆ı görülmektedir. Yine araştırma verileri cinsiyet değişkenine göre incelendiğinde hem bayan hem de erkek matematik öğretmen adaylarının GŞAYB Testine ait sontest ortalama puanlarının öntest puanlarına göre neredeyse iki katına çıktığı görülmektedir. Bunun sebebi matematik öğretmen adaylarının gerçekleştirilen öğretim sürecinde sadece işlemsel beceriler değil aynı zamanda kavramsal bilgiler de öğrenmiş olması olarak düşünülebilir. Nitekim Akkuş, Çıkla ve Duatepe (2002) yapmış oldukları çalışmalarında matematik öğretmen adaylarının akıl yürütme uygulamaları sonrasında işlemsel bilgilere sahip olduklarını ve kavramsal bilgilerin elde edilmesinde öğrenim sürecinin etkili olduğunu dile getirmişlerdir. Yapılan bu çalışmada da Cabri ve GeoGebra kullanılarak öğrenim sürecinin yürütülmesi sonucunda matematik öğretmen 
adaylarının geometrik şekiller üzerine işlemsel ve kavramsal akıl yürütme becerilerinin arttığını söylemek mümkündür.

Çalışmada betimsel istatistikler incelendikten sonra öncelikle matematik öğretmen adaylarının öntest ve sontest puanlarının cinsiyet değişkenine ilişkin anlamlı bir farklılık gösterip göstermediği araştırılmış, hem öntest hem de sontest puanlarına göre bayan ve erkek matematik öğretmen adaylarının puanlarının anlamlı bir farklılık göstermediği tespit edilmiştir. Çalışmada elde edilen bu bulgu neticesinde matematik öğretmen adaylarının öğretim sürecinden önce benzer akıl yürütme becerisine sahip olduklarını ve Cabri ve GeoGebra kullanımıyla öğretim sürecinin tamamlanması neticesinde akıl yürütme becerilerini benzer oranda geliştirdiklerini söylemek mümkündür. Büyüköztürk, Çakmak, Akgün, Karadeniz ve Demirel (2016) deneysel çalışmalar yürütürken araştırma örneklemine alınan bireylerin deneysel süreç öncesinde ve sonrasında benzer özellikte olması gerektiğini ifade etmişlerdir. Bu bulgu araştırma sonucu ile benzerlik göstermektedir.

Araştırmada sırasıyla bayan, erkek ve tüm matematik öğretmen adaylarının akıl yürütme becerilerinin öntest-sontest puanlarına göre anlamlı bir farklılık gösterip göstermediği bağımlı gruplarda t-testi yapılarak araştırılmıştır. Test sonuçlarına göre sırasıyla bayan, erkek ve tüm matematik öğretmen adaylarının sontest puanları ile öntest puanları arasında anlamlı bir farklılık bulunmuştur. Ortalamalara bakıldığında bu farkın her üç örneklem grubu için de sontestin lehine olduğu görülmektedir. Bunun sebebi öğretim sürecinin Cabri ve GeoGebra uygulamaları ile zenginleştirilmiş olması ve derse olan ilginin veya olumlu tutumun artması olarak görülebilir. Aktümen ve Kaçar (2003) yapmış oldukları çalışmalarında bilgisayar destekli geometri eğitiminin matematik öğretmenlerinin başarılarını ve tutumlarını olumlu yönde etkilediğini belirtmişlerdir. Yine Bedir (2005) yapmış olduğu çalışmasında bilgisayar destekli eğitimin öğrencilerinin başarısını artırdığını ifade etmiştir. Bu sonuçlar araştırmada bulunan sonuçlarla örtüşmektedir.

Sonuç olarak matematik öğretmen adaylarının GŞAYB düzeylerinin artmasında Cabri ve GeoGebra yazılımlarının kullanımının önemli olduğunu söylemek mümkündür. Çalışmadan elde edilen bulgular neticesinde ileride GŞAYB ile ilgili çalışmak isteyen araştırmacılara şu önerilerde bulunulabilir:

1. Cabri ve GeoGebra'nın öğretim sürecinde kullanılmasıyla GŞAYB'nin gelişimi farklı örneklem grupları üzerinde farklı branşlardaki öğretmen adayları veya farklı öğretim düzeylerinde öğrenim görmekte olan öğrenciler ile araştırılabilir. 
2. Matematik öğretmen adaylarının GŞAYB’leri üzerinde kontrol gruplu deneysel desen kullanılarak farklı öğretim tekniklerinin etkinliği araştırılabilir.

3. Güncellenen matematik öğretim programlarının ihtiva ettiği diğer becerileri GSAYB ile birlikte araştırılarak aralarındaki ilişkiler analiz edilebilir.

Bilgilendirme

Bu çalışmada kullanılan verilerin 2020 yılı öncesine ait olduğu araştırmacılar tarafından onaylanmıştır.

Yazar Katkı Beyanı

Aziz ILLHAN: Kavramsallaştırma, metodoloji, danışmanlık ve denetim (ölçme aracı, veri analizi), inceleme-yazma ve düzenleme

Recep ASLANER: Kavramsallaştırma, veri toplama, ön taslak yazımı ve düzenleme

\section{Kaynaklar}

Akar, Ü. \& Hacısalihoğlu-Karadeniz, M. (2014). Dinamik geometri yazılımının açıortay ve kenarortay öğretiminde meslek lisesi öğrencilerinin başarılarına etkisi. Journal of Computer and Education Research, 2(4), 74-90.

Aktümen, M. \& Kaçar, A. (2003). İlköğretim 8. sınıflarda harfli ifadelerle işlemlerin öğretiminde bilgisayar destekli öğretimin rolü ve bilgisayar destekli öğretim üzerine öğrenci görüşlerinin değerlendirilmesi. Kastamonu Eğitim Dergisi, 11(13). 339-358.

Alpan, G. (2008). Görsel okuryazarlık ve öğretim teknolojisi. Yüzüncü Yıl Üniversitesi Eğitim Fakültesi Dergisi, 5(1), 74-102.

Altun, M. (2009). Ĕ̆itim fakülteleri ve lise matematik öğretmenleri için liselerde matematik öğretimi (3. Baskı). Bursa: Aktüel Alfa Akademi.

Amsterlaw, J.A. (2004). Development of children's beliefs about everyday reasoning. Publishing Doctoral Thesis, University of Michigan, ABD.

Aydın, M., Laçin, S., \& Keskin, İ. (2018). Ortaöğretim matematik dersi öğretim programının uygulanmasına yönelik öğretmen görüşleri. International e-Journal of Educational Studies (IEJES), 2(3), 1-11.

Baki, A. (2001). Bilişim teknolojisi 1şığı altında matematik eğitiminin değerlendirilmesi. Milli Ĕ̆itim Dergisi, 149(1), 26-31.

Bedir, D. (2005). Bilgisayar destekli matematik öğretiminin ilköğretimde geometri öğretiminde yeri ve öğrenci başarısı üzerindeki etkisi. Yayınlanmamış Yüksek Lisans Tezi, Dokuz Eylül Üniversitesi, Eğitim Bilimleri Enstitüsü, İzmir.

Brown, M., Jones, K., \& Taylor, R. (2003). Developing geometrical reasoning in the secondary school: Outcomes of trialling teaching activities in classrooms. A Report from the Southampton/Hampshire Group to the Qualifications and Curriculum Authority. Full report available online at: www.crme.soton.ac.uk/research/geomreason. 
Büyüköztürk, Ş. (2016). Veri analizi el kitabı (22. Baskl). Ankara: Pegem Akademi.

Büyüköztürk, Ş., Çakmak, E. K., Akgün, Ö. E., Karadeniz, Ş., \& Demirel, F. (2016). Bilimsel araştırma yöntemleri. Ankara: Pegem A Yayıncılık.

Çiftçi, O. \& Tatar, E. (2014). Pergel-cetvel ve dinamik bir yazılım kullanımının başarıya etkilerinin karşılaştırılması. Journal of Computer and Education Research, 2(4), 111-133.

Çubukçu, Z. (2004). Öğretmen adaylarının düşünme stillerinin öğrenme biçimlerini tercih etmelerindeki etkisi. İnönü Üniversitesi Ĕ̆itim Fakültesi Dergisi, 1(1). 1-19.

Gomes, A.S. \& Vergnaud, G. (2004). On the learning of geometric concepts using dynamic geometry software. Novas Technologi Asna Educaçao, 2(1), 12-15.

Güven, B. (2002). Dinamik geometri yazılımı Cabri ile keşfederek öğrenme. Yayınlanmamış yüksek lisans tezi, Karadeniz Teknik Üniversitesi, Fen Bilimleri Enstitüsü, Trabzon.

Güven, B. \& Karatas, S. (2003). Dinamik geometri yazılımı Cabri ile geometri öğrenme: öğrenci görüşleri. Turkish Online Journal of Educational Technology, 2(2).

İbili, E. (2019).The use of dynamic geometry software from a pedagogical perspective: current status and future prospects. Journal of Computer and Education Research, 7(14), 337-355.

Karasar, N. (1991). Bilimsel araştırma yöntemi (4. Basım). Ankara: Nadir Kitap Yayınevi.

Köseoğlu, F., Tümay, H., \& Budak, E. (2008). Bilimin doğası hakkında paradigma değişimleri ve öğretimi ile ilgili yeni anlayışlar. Gazi Eğitim Fakültesi Dergisi, 28(2), 221-237.

Lawson, A.E. (2005). What is the role of induction and deduction in reasoning and scientific inquiry. Journal of Reseach in Science Teaching, 42(6), 716-740.

Milli Eğitim Bakanlığı. [MEB] (2005). İlköğretim matematik dersi 6-8. sınıflar öğretim programı. https://ttkb.meb.gov.tr adresinden 28.02.2018 tarihinde erişilmiştir.

Milli Eğitim Bakanlığı. [MEB] (2013). Ortaokul matematik dersi öğretim programı. https://ttkb.meb.gov.tr adresinden 08.02.2013 tarihinde erişilmiştir.

Milli Eğitim Bakanlığı. [MEB] (2018). Matematik dersi öğretim programı (ilkokul ve ortaokul 1, 2, 3,4,5,6,7 ve 8. sinfflar). https://ttkb.meb.gov.tr adresinden 12.02 .2018 tarihinde erişilmiştir.

National Research Council [NRC].(1996). National science education standards. Washington DC: National Academy Press.

Oaksford, M. (2005). Reasoning. In nick brais by \& angus gellatly, cognitive psychology, New York: Oxford University Press Inc.

Royal Society \& Joint Mathematical Council (2001). Teaching and learning geometry 11-19. Report of a Royal Society/Joint Mathematical Council working group, retrived from at 10.04.2017: https://royalsociety.org/ /media/Royal Society Content/policy/publications/2001/9992.pdf

Tall, D.O., Blockland, P., \& Kok, D. (1990). A graphic approach to the calculus. IBM compatibles computers with CGA, EGA or Hercules graphics, Sunburst Inc, USA.

Topuz, F. \& Birgin, O. (2020). Yedinci sınıf "çember ve daire" konusunda geliştirilen geogebra destekli öğretim materyaline ve öğrenme ortamına ilişkin öğrenci görüşleri. Journal of Computer and Education Research, 8(15), 1-27. DOI:10.18009/jcer.638142

Umay, A., Duatepe, A., \& Akkuş-Çıkla, O. (2005, Eylül). Sınıf öğretmeni adaylarının yeni öğretim programındaki matematiksel içeriğe yönelik hazır bulunuşluk düzeyleri. XIV. Ulusal Eğitim Bilimleri Kongresi, Pamukkale Üniversitesi, Eğitim Fakültesi 28-30 Eylül. 
1. Hafta: Deney süreci hakkında bilgi verilmesi ve GŞAYB Testinin ön test olarak uygulanması

2. Hafta: Cabri programının öğretmen adaylarına tanıtılması, bu programın sahip olduğu özellikler kullanılarak öğretmen adaylarıyla beraber öğretim sürecine dâhil edilen geometrik şekillerin oluşturulması.

3. Hafta: Cabri programında öteleme, dönme, ölçümler yapma, makrolar oluşturma ve animasyon verme işlemlerinin uygulanması.

4. Hafta: Cabri programında oluşturulan doğru parçasını ve oluşturulan açıyı bulunduğu yerden farklı bir alana taşıma uygulamasının yapılması.

5. Hafta: Cabri programında herhangi bir açıyı üç eşit parçaya bölen makronun oluşturulması ve bu makro yardımıyla Morley Teoreminin ispatının yapılması.

6. Hafta: Cabri programında bir doğruya dışındaki herhangi bir noktadan paralel doğru çizilmesi ve bu uygulama yardımıyla paralelkenarların oluşturulması.

7. Hafta: Cabri programında bulunan bir doğruya üzerindeki herhangi bir noktadan dikme çizme seçeneğinin kullanılması ve bu komut ile kare ve dikdörtgen şekillerinin oluşturulması.

8. Hafta: Cabri programında seçilen bir doğru parçasının orta noktasının bulunması ve bu nokta yardımıyla orta dikme doğrusunun çizilmesi. Ayrıca bu işlemler yardımıyla herhangi bir üçgenin çevrel çemberini çizebilen makronun tanımlanması.

9. Hafta: Cabri programında seçilen bir doğruya dışındaki herhangi bir noktadan dik doğru inşa edilmesi. Orthic Üçgen ve özelliklerinin öğretilmesi, çizilerek makrosunun oluşturulması.

10. Hafta: Cabri programıyla Pisagor bağıntısı ve özelliklerinin araştırılması. Pisagor ağacının makrolar yardımıyla çizilmesi.

11. Hafta: GeoGebra dinamik programının özelliklerinin tanıtılması, öğretmen adaylarıyla birlikte nokta, doğru, doğru parçası, ışın, üçgen, dikdörtgen, kare, çokgenler ve düzgün çokgenler üzerinde uygulamalar yapilması.

12. Hafta: GeoGebra Programı ile piramit ve prizma gibi geometrik şekillerin ve cisimlerin inşa edilmesi.

13. Hafta: GeoGebra programında oluşturulan geometrik şekillerin inşa edilen bir düzlemle arakesit eğrilerinin incelenmesi. Koniklerin GeoGebra programında oluşturulması.

14. Hafta: Genel tekrarın yapılması ve GŞAYB Testinin son test olarak uygulanması.

JCER's Publication Ethics and Publication Malpractice Statement are based, in large part, on the guidelines and standards developed by the Committee on Publication Ethics (COPE). This article is available under Creative Commons CC-BY 4.0 license (https://creativecommons.org/licenses/by/4.0/) 